\title{
FIP1L1/PDGFRA Fusion Protein
}

National Cancer Institute

\section{Source}

National Cancer Institute. FIP1L1/PDGFRA Fusion Protein. NCI Thesaurus. Code C99744.

A fusion protein $(849, \sim 95 \mathrm{kDa}$ ) encoded by the FIP1L1/PDGFRA fusion gene. This protein is comprised of the first 339 amino acids of pre-mRNA 3'-end-processing factor FIP1, fused to the C-terminal cytoplasmic domains of the alpha-type platelet-derived growth factor receptor protein, including the protein kinase domain. 